\title{
Ventilation-induced lung injury exists in spontaneously breathing patients with acute respiratory failure: Yes
}

\author{
Laurent Brochard ${ }^{1,2^{*}}$
}

@ 2016 Springer-Verlag Berlin Heidelberg and ESICM

\section{Introduction}

Critical care medicine has entered a new era characterized by the pre-eminence of pathophysiological medicine, mixing evidence, experience and a physiology-based approach. Physiology is a fundamental part of the knowledge needed to manage critically ill patients, but there is a large gap between knowing what is normal, i.e. physiology, and knowing what are the best solutions to cope with diseases, i.e. pathophysiology, if any. After the birth of critical care in 1952 in the Blegdham Hospital in Copenhagen [1], mechanical ventilation was universally recognized as a life-saving technique. It took many years to realize that mechanical ventilation delivered to reproduce normal physiology, i.e. achieving normal gas exchange, could injure the lungs and harm the patient [2-4]. We collectively realized, at the expense of entire research programs, that a lung-protective ventilation was necessary [5]. We still do not understand everything, like the undisputable, though paradoxical, beneficial effect of PEEP, in a situation where "hyperinflation" was considered as the culprit. Because everything could not fit with too simple a theory, we also had hard debates around the hemodynamic effects of ventilation, often forgotten when we look at the lung [6]. Last, despite accumulating evidence, we also failed to recognize that the potential mechanisms causing ventilator-induced lung injury were for many of them simply reflecting ventilation-induced lung injury, whatever the source of breathing.

\footnotetext{
*Correspondence: brochardl@smh.ca

${ }^{2}$ Department of Critical Care, St Michael's Hospital, Keenan Research Centre and Li Ka Shing Knowledge Institute, 30 Bond Street, Toronto, ON M5B 1W8, Canada

Full author information is available at the end of the article
}

For contrasting viewpoints, please go to doi:10.1007/s00134-016-4483-4 and doi:10.1007/s00134-016-4488-z.

\section{Evidence of ventilation-induced lung injury during spontaneous breathing}

Mascheroni and colleagues demonstrated in 1988 that spontaneous hyperventilation could injure the lungs in a brilliant classical experiment [7], which, very similarly to the Webb and Tierney seminal paper [4], remained underappreciated for many years. They injected salicylate acid into the magna cisterna of spontaneously breathing large animals in order to generate a strong central metabolic acidosis and stimulate ventilation. Interestingly, they had two control groups, including one group of animals made acidotic but paralyzed to prevent hyperventilation. This demonstrated that the effects were not directly caused by the acidosis. What they showed by following the hyperventilating animals was that their oxygenation progressively worsened, and that at autopsy they had developed pulmonary edema and injury similar to what was later called ventilation-induced lung injury.

Regarding the possibility of injurious spontaneous breathing on top of mechanical ventilation, Yoshida and colleagues have performed a series of experiments demonstrating the worsening of lung injury by spontaneous ventilation in mechanically ventilated animals with lung injury [8]. Interestingly, they found that the effects of spontaneous ventilation depended on the degree of lung injury. In mild injury, adding spontaneous breathing on top of a monotonous mechanical ventilation was beneficial, while the opposite was observed in severe lung injury. In patients with the acute respiratory distress syndrome (ARDS), Papazian et al. demonstrated in a series of clinical studies terminated by a large randomized clinical trial that blocking spontaneous breathing with neuromuscular blockers for $48 \mathrm{~h}$ decreased lung inflammation [9] and improved survival [10]. Although we do not know the precise mechanisms, this strongly

\section{实


suggested a deleterious effect of spontaneous breathing under mechanical ventilation. Spontaneous breathing could increase ventilation by breath stacking [11] or reverse triggering [12], but Yoshida et al. also showed that, without increasing tidal volume, spontaneous ventilation with a high respiratory drive could induce an internal redistribution of the inspired tidal volume generating local injurious forces [13]. Recently, we proposed the concept of patient self-inflicted lung injury (P-SILI) to describe all these conditions where a high respiratory drive induced by local lung injury could result in global or regional pressure changes susceptible to aggravating the initial lung injury [14].

\section{Differences between spontaneous breathing and mechanical ventilation}

In theory, the same transpulmonary pressure swings can be generated by controlled mechanical ventilation, partially assisted ventilation or spontaneous breathing. In a series of patients submitted to different levels of pressure support and to controlled mechanical ventilation, and in whom transpulmonary pressure was measured as airway minus esophageal pressure, Bellani et al. checked that this assumption held true [15]. Indeed, when breaths were matched to have the same volume and flow, transpulmonary swings were identical whatever the modality of ventilation. Alveolar pressure, however, differed because of the different distributions of the respective pressures. The higher the negative swings in esophageal pressure, the lower the mean alveolar pressure, which rapidly fell below PEEP for low levels of support. So a lower than set PEEP or a frankly negative alveolar pressure could favor the generation of pulmonary edema in cases of previous vascular leakage. Negative pressure pulmonary edema has been well described, and such a phenomenon could participate in the risks of spontaneous ventilation [16].

\section{Clinical relevance for noninvasive ventilation}

Recently, Carteaux et al. have been the first to carefully monitor the tidal volumes generated by patients with hypoxemic respiratory failure under noninvasive ventilation [17]. Their observations brought three important conclusions: (1) it is impossible to control the tidal volume by manipulating the pressure support level on top of a low PEEP; (2) patients who fail and need intubation have higher tidal volumes than successful patients; and (3) an average tidal volume at $9.5 \mathrm{ml} / \mathrm{kg}$ or above of predicted body weight was highly predictive of failure. Also, as shown previously in many studies, the outcome of intubated patients failing NIV was poor [18]. Interestingly, a recent study showed that the use of the helmet as an interface for NIV was associated with a better outcome than the traditional oronasal face mask [19].
Whether the possibility to deliver higher PEEP could be part of the explanation is not known. Higher PEEP could reduce the drive and the negative pressure swings. Lastly, the high flow nasal cannula technique has shown remarkable results in this indication, with an improved survival in non-intubated patients by comparison with simple oxygen therapy or noninvasive ventilation [20]. The benefit may result from the washout of the oropharyngeal dead space, reducing the ventilatory needs and the work of breathing, per breath or per minute, since the respiratory rate most often drops with this technique.

\section{Monitoring the patient spontaneous breathing activity}

In patients under partial ventilatory assist, clinicians should not consider that their patients are "protected" because they set only modest levels of positive airway pressure during inspiration using pressure support ventilation. To better understand what forces the patient is generating, a monitoring of respiratory muscle activity and/or respiratory drive is necessary. The occlusion pressure, also referred to as $\mathrm{P} 0.1$ for the negative pressure generated at $0.1 \mathrm{~s}$ of an occlusion, is a reasonably good index of the respiratory drive and should be used much more widely at the bedside to detect patients at high risk of P-SILI [21, 22].

\section{Conclusion}

Ventilation-induced lung injury and P-SILI is a reality. We should consider noninvasive techniques well adapted to minimize these risks but also consider mechanical ventilation as a necessary treatment in some cases. Intubation, sedation and paralysis may be necessary to efficiently deliver a lung-protective ventilation.

\footnotetext{
Author details

${ }^{1}$ Interdepartmental Division of Critical Care Medicine, University of Toronto, Toronto, Canada. ${ }^{2}$ Department of Critical Care, St Michael's Hospital, Keenan Research Centre and Li Ka Shing Knowledge Institute, 30 Bond Street, Toronto, ON M5B 1W8, Canada.

Received: 2 December 2016 Accepted: 8 December 2016 Published online: 10 January 2017

References

1. Trubuhovich RV (2004) August 26th 1952 at Copenhagen: 'Bjorn Ibsen's Day'; a significant event for anaesthesia. Acta Anaesthesiol Scand 48:272-277

2. Dreyfuss D, Saumon G (1994) Ventilation-induced injury. In: Tobin MJ (ed) Principles and practice of mechanical ventilation. McGraw Hill, New York, pp 793-811

3. Tremblay L, Valenza F, Ribeiro SP, Li J, Slutsky AS (1997) Injurious ventilatory strategies increase cytokines and c-fos m-RNA expression in an isolated rat lung model. J Clin Invest 99:944-952
} 
4. Webb HH, Tierney DF (1974) Experimental pulmonary edema due to intermittent positive pressure ventilation with high inflation pressures. Protection by positive end-expiratory pressure. Am Rev Respir Dis 110:556-565

5. The Acute Respiratory Distress Syndrome Network (2000) Ventilation with lower tidal volumes as compared with traditional tidal volumes for acute lung injury and the acute respiratory distress syndrome. N Engl J Med 342:1301-1308

6. Mekontso Dessap A, Charron C, Devaquet J, Aboab J, Jardin F, Brochard L, Vieillard-Baron A (2009) Impact of acute hypercapnia and augmented positive end-expiratory pressure on right ventricle function in severe acute respiratory distress syndrome. Intensive Care Med 35:1850-1858

7. Mascheroni D, Kolobow T, Fumagalli R, Moretti MP, Chen V, Buckhold D (1988) Acute respiratory failure following pharmacologically induced hyperventilation: an experimental animal study. Intensive Care Med 15:8-14

8. Yoshida T, Uchiyama A, Matsuura N, Mashimo T, Fujino Y (2013) The comparison of spontaneous breathing and muscle paralysis in two different severities of experimental lung injury. Crit Care Med 41:536-545

9. Forel J, Roch A, Marin V, Michelet P, Demory D, Blache J, Perrin G, Gainnier M, Bongrand P, Papazian L (2006) Neuromuscular blocking agents decrease inflammatory response in patients presenting with acute respiratory distress syndrome. Crit Care Med 34:2749-2757

10. Papazian L, Forel JM, Gacouin A, Penot-Ragon C, Perrin G, Loundou A, Jaber S, Arnal JM, Perez D, Seghboyan JM, Constantin JM, Courant P, Lefrant JY, Guerin C, Prat G, Morange S, Roch A (2010) Neuromuscular blockers in early acute respiratory distress syndrome. N Engl I Med 363:1107-1116

11. Beitler J, Sands S, Loring S, Owens R, Malhotra A, Spragg R, Matthay M, Thompson B, Talmor D (2016) Quantifying unintended exposure to high tidal volumes from breath stacking dyssynchrony in ARDS: the BREATHE criteria. Intensive Care Med 42:1427-1436

12. Akoumianaki E, Lyazidi A, Rey N, Matamis D, Perez-Martinez N, Giraud R, Mancebo J, Brochard L, Marie Richard JC (2013) Mechanical ventilationinduced reverse-triggered breaths: a frequently unrecognized form of neuromechanical coupling. Chest 143:927-938

13. Yoshida T, Torsani V, Gomes S, De Santis RR, Beraldo MA, Costa EL, Tucci MR, Zin WA, Kavanagh BP, Amato MB (2013) Spontaneous effort causes occult pendelluft during mechanical ventilation. Am J Respir Crit Care Med 188:1420-1427
14. Brochard L, Slutsky A, Pesenti A (2016) Mechanical ventilation to minimize progression of lung injury in acute respiratory failure. Am J Respir Crit Care Med. doi:10.1164/rccm.201605-1081CP

15. Bellani G, Grasselli G, Teggia-Droghi M, Mauri T, Coppadoro A, Brochard L, Pesenti A (2016) Do spontaneous and mechanical breathing have similar effects on average transpulmonary and alveolar pressure? A clinical crossover study. Crit Care 20:142

16. Bhattacharya M, Kallet RH, Ware LB, Matthay MA (2016) Negative-pressure pulmonary edema. Chest 150:927-933

17. Carteaux G, Millan-Guilarte T, De Prost N, Razazi K, Abid S, Thille AW, Schortgen F, Brochard L, Brun-Buisson C, Mekontso Dessap A (2016) Failure of noninvasive ventilation for de novo acute hypoxemic respiratory failure: role of tidal volume. Crit Care Med 44:282-290

18. Antonelli M, Conti G, Moro M, Esquinas A, Gonzalez-Diaz G, Confalonieri M, Pelaia P, Principi T, Gregoretti C, Beltrame F, Pennisi M, Arcangeli A, Proietti R, Passariello M, Meduri G (2001) Predictors of failure of noninvasive positive pressure ventilation in patients with acute hypoxemic respiratory failure: a multi-center study. Intensive Care Med 27:1718-1728

19. Patel BK, Hall JB, Kress JP (2016) Face mask vs helmet for noninvasive ventilation-reply. JAMA 316:1497

20. Frat JP, Thille AW, Mercat A, Girault C, Ragot S, Perbet S, Prat G, Boulain T, Morawiec E, Cottereau A, Devaquet J, Nseir S, Razazi K, Mira JP, Argaud L, Chakarian JC, Ricard JD, Wittebole X, Chevalier S, Herbland A, Fartoukh M, Constantin JM, Tonnelier JM, Pierrot M, Mathonnet A, Beduneau G, Deletage-Metreau C, Richard JC, Brochard L, Robert R, Group FS, Network $R$ (2015) High-flow oxygen through nasal cannula in acute hypoxemic respiratory failure. N Engl J Med 372:2185-2196

21. Mancebo J, Albaladejo P, Touchard D, Bak E, Subirana M, Lemaire F, Harf A, Brochard L (2000) Airway occlusion pressure to titrate positive endexpiratory pressure in patients with dynamic hyperinflation. Anesthesiology 93:81-90

22. Milic-Emili J, Whitelaw WA, Derenne JP (1975) Occlusion pressure: a simple measure of the respiratory center's output. N Engl J Med 293:1029-1030 